\title{
三维石墨烯纳米球的制备及其在锂离子电池中的应用
}

\author{
徐 丽, 盛鹏，陈新，韩 钰，刘双宇，王 博，赵广耀，刘海镇
}

(全球能源互联网研究院 先进输电技术国家重点实验室，电工新材料技术联合实验室，北京 102211)

摘 要: 采用直流电弧放电法制备出一种三维石墨烯纳米球材料。采用扫描电镜(SEM)、透射电镜(TEM)、拉曼光 谱和 $\mathrm{X}$ 射线衍射光谱(XRD)等测试方法对三维石墨烯纳米球的形貌和结构进行了表征和研究。通过交流阻抗 (EIS)、恒流充放电和循环稳定性测试等电化学测试手段来研究三维石墨烯纳米球作为锂离子电池负极材料的电 化学性能。结果表明, 在电流密度为 $0.05 \mathrm{~A} / \mathrm{g}$ 下, 三维石墨烯纳米球作为锂离子电池负极材料的首次放电容量为 $485.9 \mathrm{mAh} / \mathrm{g}$, 高于炭黑作负极的放电容量 $(401 \mathrm{mAh} / \mathrm{g})$; 当电流密度为 $1 \mathrm{~A} / \mathrm{g}$ 时, 三维石墨烯纳米球负极材料仍然 具有 $185.4 \mathrm{mAh} / \mathrm{g}$ 的放电容量。在电流密度分别为 $0.5 \mathrm{~A} / \mathrm{g}$ 和 $2.5 \mathrm{~A} / \mathrm{g}$ 下, 充放电循环 100 次以后, 三维石墨烯纳米 球的比容量几乎没有衰减, 这表明三维石墨烯纳米球作为锂离子电池的负极材料比炭黑具有更大的容量, 同时具 有优异的循环稳定性。

关 键 词: 三维石墨烯; 纳米球; 锂离子电池

中图分类号: TQ174 文献标识码: A

\section{Preparation and Application of Three-dimensional Graphene Nanospheres in Lithium Ion Battery}

XU Li, SHENG Peng, CHEN Xin, HAN Yu, LIU Shuang-Yu, WANG Bo, ZHAO Guang-Yao, LIU Hai-Zhen

(Materials Laboratory of State Grid Corporation of China, State Key Laboratory of Advanced Transmission Technology, Global

Energy Interconnection Research Institute, Beijing 102211, China)

\begin{abstract}
Three-dimensional graphene nanospheres were prepared by direct-current arc discharge method. The microstructure and morphology of the graphene nanospheres were characterized by transmission electron microscope (TEM), scanning electron microscope (SEM), Raman spectrum and X-ray diffraction (XRD) pattern. The electrochemical properties of the three-dimensional graphene nanospheres as the anode materials of lithium ion battery were studied by alternating current impedance and constant current charge-discharge cycle performance. The results show that, at current density of $0.05 \mathrm{~A} / \mathrm{g}$, the graphene nanospheres as the anode materials have a high first discharge capacity of $485.9 \mathrm{mAh} / \mathrm{g}$, which is better than has the carbon black $(401 \mathrm{mAh} / \mathrm{g})$. When the current density increases to $1 \mathrm{~A} / \mathrm{g}$, the three-dimensional nanospheres can still achieve a capacity of $185.4 \mathrm{mAh} / \mathrm{g}$. The three-dimensional nanospheres have little capacity decay after 100 cycles at current density of $0.5 \mathrm{~A} / \mathrm{g}$ and $2.5 \mathrm{~A} / \mathrm{g}$. The results show that the three-dimensional graphene nanospheres have a higher capacity than carbon black as the anode for lithium ion battery, and they have excellent cycling stability, too.
\end{abstract}

Key words: three dimensional graphene; nanosphere; lithium ion battery 
石墨烯是一种从石墨中剥离出来, 由碳原子组 成的只有一个原子层厚度的蜂窝状二维晶体。它是 构成一系列碳材料(零维富勒烯, 一维碳纳米管, 三 维石墨)的基本骨架 ${ }^{[1-3]}$ 。自 2004 年石墨烯被发现以 来, 发现了它的许多神奇性能, 吸引了广泛关注。这 些优异的性质包括大比表面积 ${ }^{[4]}$ 、高杨氏模量 ${ }^{[5]}$ 、 高导热率 ${ }^{[6]}$ 、高电子迁移率 ${ }^{[7]}$ 等。目前, 科学家们正 在探索把石墨烯的优异性能应用到各个领域, 如 高速光电设备 ${ }^{[8-9]}$ 、能源转换与存储 ${ }^{[0-11]}$ 、化学传 感器 ${ }^{[12]}$, 甚至是 DNA 测序 ${ }^{[13-14]}$ 等。其中, 石墨烯优 异的电学性能和高比表面积, 使其在锂离子电池领 域具有巨大应用潜力。

石墨烯的片层比较柔韧, 可以有效缓冲电极材 料的体积膨胀, 并且石墨烯存储锂离子的活化位点 比较多, 使其理论容量远高于传统的石墨材料。这极 大地提高了电池的储锂容量, 从而得到比较高的能 量密度。石墨烯材料由于其特殊的结构, 使得锂离子 在其中的扩散路径变得比较短, 又因为其电导率高, 可以明显地提高锂离子电池的倍率性能。因而, 以石 墨烯作为锂离子电池的负极材料具有很大的应用潜 能。Guo 等 ${ }^{[15]}$ 报道的石墨烯纳米球 $(\mathrm{GNs})$ 具有相对较 高的可逆容量 $(672 \mathrm{mAh} / \mathrm{g})$ 和良好的循环性能。Pan 等 ${ }^{[16]}$ 指出具有无序结构的 GNs 因其边缘和其它部位 的缺陷导致更多的 $\mathrm{Li}$ 存储位点, 所以具有更高的可 逆容量(784 1054 mAh/g)。尽管如此, 获得具有高比 容量、优异倍率性能且同时兼顾高循环稳定性的石 墨烯锂离子电池负极材料一直是研究的难点。

本工作以直流电弧放电方法制备三维石墨烯纳 米球, 制备得到的三维石墨烯纳米球相互连接形成 多孔的三维纳米结构, 这些空隙有利于 $\mathrm{Li}^{+}$的传输。

而且, 石墨烯纳米球壁是具有少层石墨烯片的中空 结构, 这种结构有利于更多量的 $\mathrm{Li}^{+}$插入到三维石墨 烯纳米球中。以三维石墨烯纳米球为锂离子电池正 极材料、锂片作为负极组装成纽扣电池, 相比于炭黑, 电池表现出高的比容量和优异的循环稳定性。

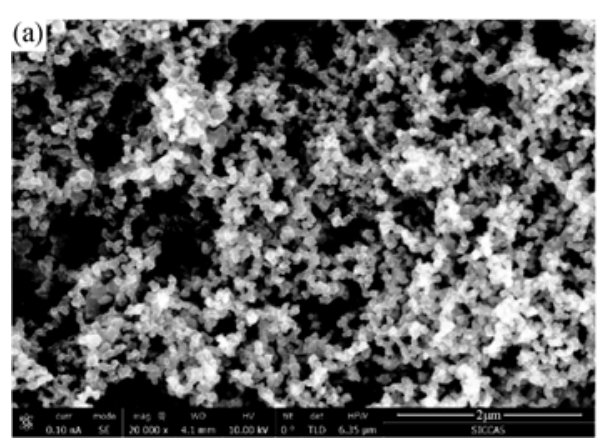

\section{1 实验方法}

\section{1 石墨烯纳米球的制备}

搭建一个直流电弧放电装置, 其中有两个为 $8 \mathrm{~mm}$ 的纯石墨棒电极, 阴极固定在装置的铜基座 上。首先装置抽真空至 $3 \mathrm{~Pa}$, 然后向其中充入 $\mathrm{He}$ 和 $\mathrm{C}_{2} \mathrm{H}_{2}$ (比例为 $1: 1$ ), 并使压力维持在 $80 \mathrm{kPa}$, 此 时设备电流为 $120 \mathrm{~A}$ 。当两个电极靠近时, 放电开 始进行并形成等离子体。当阳极开始反应时, 开始 旋转阴极并维持阴阳两极的距离为 $2 \mathrm{~mm}$, 反应时 间为 $5 \mathrm{~min}$, 最后有 $10 \mathrm{~cm}$ 阴极石墨被消耗掉。反应 结束后，等装置降到常压后收集反应室墙上的黑色 物质, 所得到的黑色物质即为三维石墨烯纳米球。

\section{2 锂离子电池的制备与性能测试}

电极制备采用铜片作为集电体, 聚偏氟乙烯 (PVDF) 作为粘结剂, 活性材料石墨烯纳米球与粘结 剂的质量比为 $7.5: 2.5$ 。将按质量比称量的石墨烯纳 米球和 PVDF, 全速摚拌 $4 \mathrm{~h}$ 后, 获得黏糊状的原料, 并均匀地涂覆于铜片, 然后放入 $80^{\circ} \mathrm{C}$ 的烘箱里烘干, 压成 $\phi 13 \mathrm{~mm}$ 的圆片。以三维石墨烯纳米球作为电池 的正极材料, 锂金属片作为电池的负极, $1 \mathrm{~mol} / \mathrm{L} \mathrm{LiClO}_{4}$ 的碳酸乙烯酯/碳酸二乙酯(体积比 $1: 1$ ) 溶液作为 电解液, 组成模拟电池。对照组以炭黑作为活性材 料, 按照同样方法组装成电池。采用恒电流充放的 方法进行电池测试。仪器采用武汉力兴测试设备仪 器有限公司制备的电池程控测试仪, 充放电电流为: $0.05 \sim 2.5 \mathrm{~A} / \mathrm{g}$, 充放电电压范围为 $0 \sim 3.0 \mathrm{~V}$ 。

\section{2 结果与讨论}

\section{1 表面形貌和结构表征}

图 1 是三维石墨烯纳米球的 SEM 照片, 由图可 以看到, 所获得的三维石墨烯纳米球的形貌为球形 结构, 其直径尺寸范围在 40 60 nm 之间, 这些球相

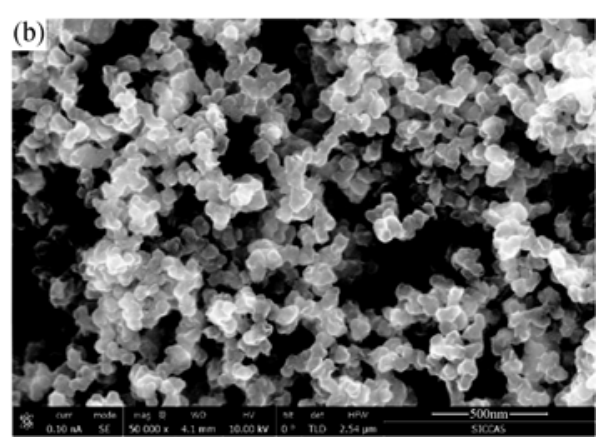

图 1 三维石墨烯纳米球的(a)低倍和(b)高倍 SEM 照片

Fig.1 (a) Low resolution and (b) high resolution SEM images of three dimensional graphene nanospheres 
互连接形成了多孔的三维纳米结构, 这些多孔的结 构有利于 $\mathrm{Li}^{+}$的插入。

图 2 展示了三维石墨烯纳米球的透射电镜 (TEM)照片, 从图 2(a)可以看到, 三维石墨烯纳米 球中存在着直径为 5 15 $\mathrm{nm}$ 的中空而无规则的空 心壳。从图 2 (b)中可以发现纳米球壁是具有多层 石墨烯片的中空结构，这种结构有利于更多量的 $\mathrm{Li}^{+}$插入到三维石墨烯纳米球中, 可以极大的提高 三维石墨烯纳米球作为锂离子电池负极材料时电 池的比容量。

图 3 是三维石墨烯纳米球和炭黑的 Raman 和 XRD 图谱。图 3(a)Raman 图有 D 峰、G 峰、2D 峰 三个峰，对应的拉曼位移分别为 $1340 、 1580$ 、 $2700 \mathrm{~cm}^{-1}$ 。三维石墨烯纳米球的 2D 峰强度比较显 著, $I_{2 \mathrm{D}} / I_{\mathrm{G}}$ 约为 0.52 , 而炭黑的 $2 \mathrm{D}$ 峰几乎没有, 表 明石墨烯纳米球为石墨烯多层结构。同时还可以发 现 $I_{\mathrm{D}} / I_{\mathrm{G}}$ 约为 1.1 , 可以知道石墨烯纳米球存在着一 定程度缺陷。这与透射电镜照片结果符合。图 3(b)XRD 图谱中石墨烯纳米球和炭黑都存在 (002) 峰, 但是石墨烯纳米球的峰位高于炭黑的峰位, 且 其半峰宽窄于炭黑。并且, 石墨烯纳米球的 XRD 图谱中(100)和(101)峰分开, 而炭黑仅有(100)峰。
上述结果表明, 石墨烯纳米球的结晶性明显好于 炭黑的结晶性。

\section{2 电化学性能表征}

图 4(a)是三维石墨烯纳米球和炭黑作为锂离子 电池负极材料所测得的电化学阻抗谱 (EIS), 从图 中可以看到从高频区到低频区存在着一个准半圆形 状，代表电荷转移电阻，而在低频区是一个直斜线， 代表溶液欧姆压降。电荷转移电阻的大小由半圆的 直径决定, 主要是由电荷在电解液与电极的界面之 间的传输所引起的，电阻为 $108.1 \Omega$, 小于炭黑作为 负极的电极电荷转移电阻 $(123.8 \Omega)$, 说明三维石 墨烯纳米球作为负极比炭黑具有更好的导电性能以 及更好的电荷转移效率。三维石墨烯纳米球作为负 极时, $\mathrm{Li}^{+}$电荷迁移阻力小于炭黑作为负极时 $\mathrm{Li}^{+}$迁 移阻力。因此, 三维石墨烯纳米球在锂离子电池上 显示出更好的潜在应用优势。

图 4(b)是三维石墨烯纳米球的第 1、2、5 次充 放电曲线, 由图可知, 以三维石墨烯纳米球作为锂 离子电池的负极材料，首次放电过程中，在 $0.8 \mathrm{~V}$ 附 近存在着一个电位平台。这个电位平台对应着电解 液的电化学还原, 在三维石墨烯纳米球表面形成了 固体电解质的中间相膜(SEI 膜)。而在第 2、5 次放
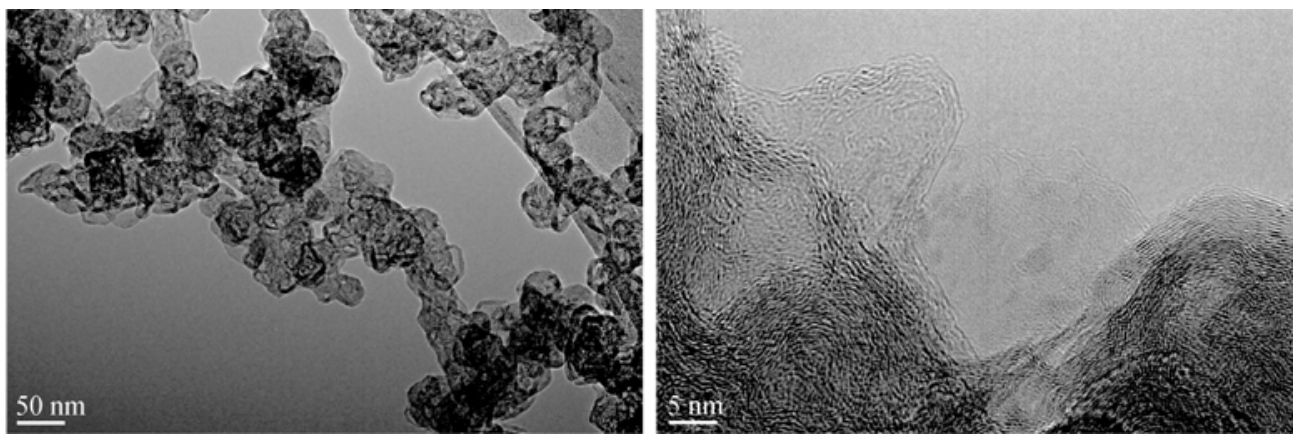

图 2 三维石墨烯纳米球的(a)低倍和(b)高倍 TEM 照片

Fig. 2 (a) Low resolution and (b) high resolution TEM images of three dimensional graphene nanospheres
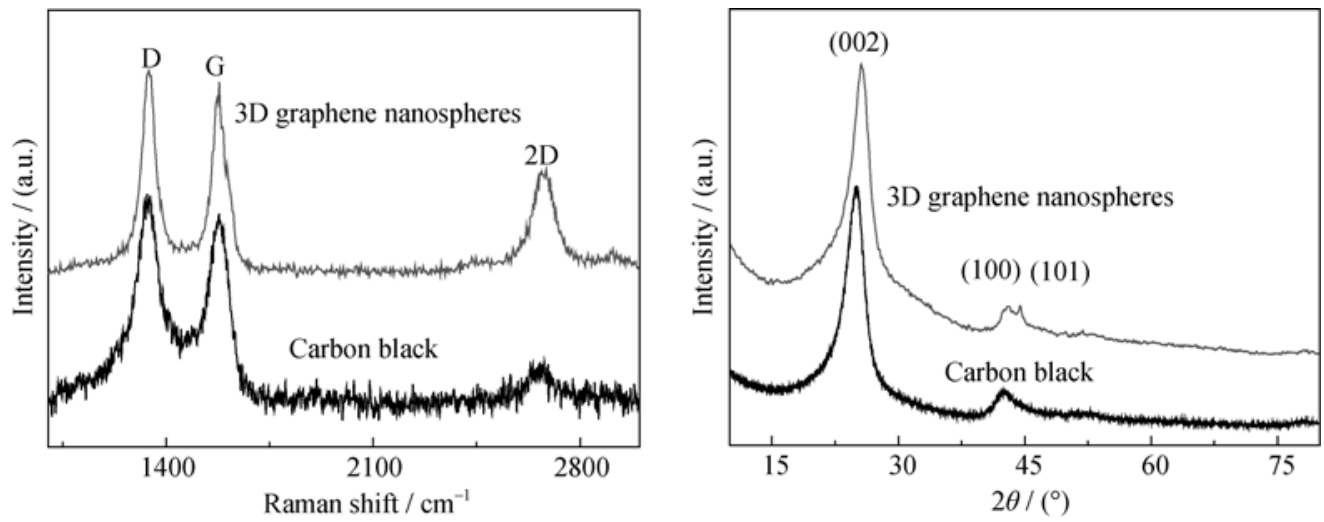

图 3 三维石墨烯纳米球和炭黑的(a) Raman 和(b) XRD 图谱

Fig. 3 (a) Raman spectra and (b) XRD patterns of three dimensional graphene nanospheres and carbon black 

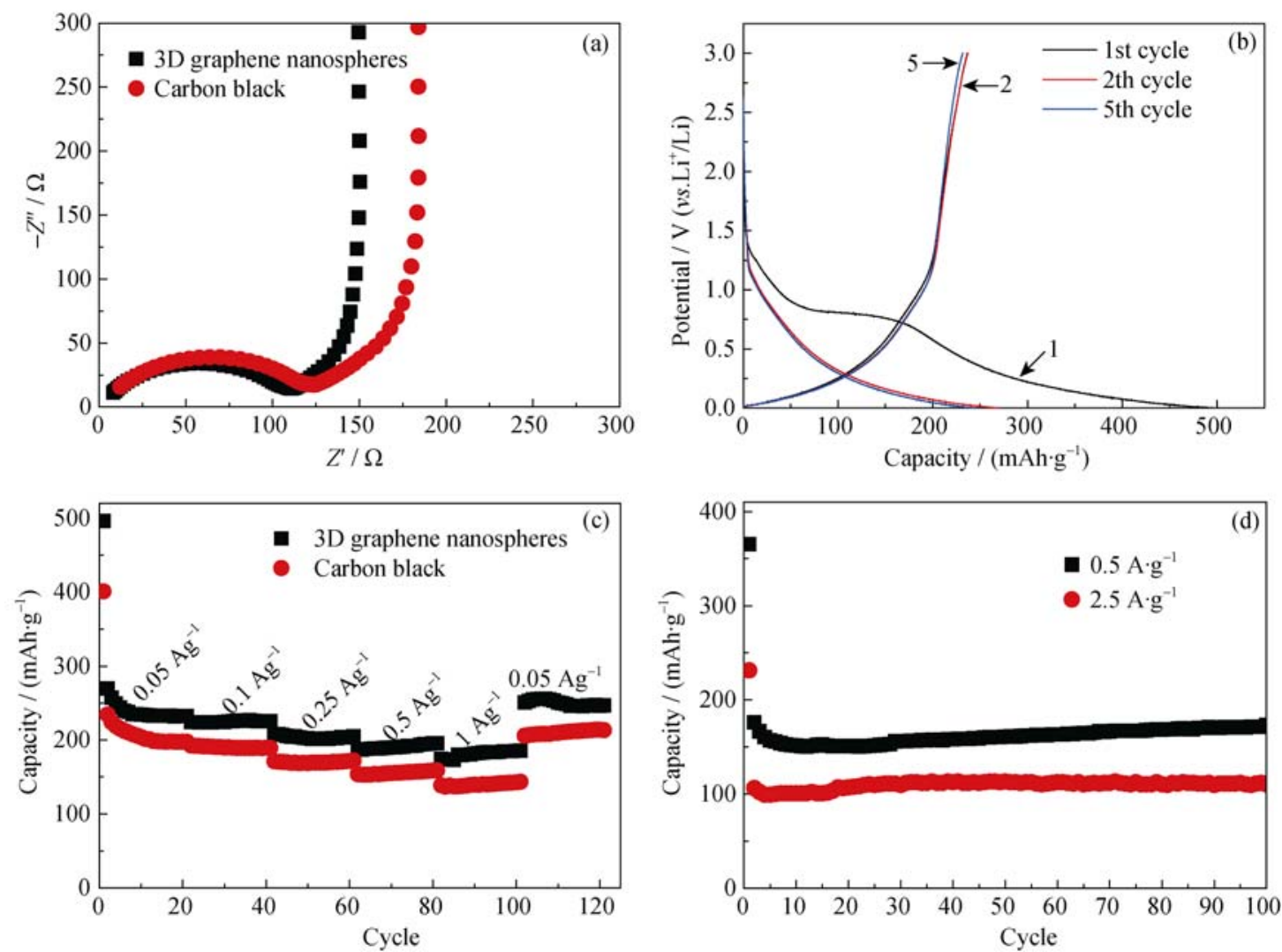

图 4 样品的电化学性能

Fig. 4 Electrochemical properties of the samples

(a) Electrochemical impedance spectra of three dimensional graphene nanospheres and carbon black electrodes, (b) Galvanostatic charge-discharge curves of three dimensional graphene nanospheres at $0.05 \mathrm{~A} / \mathrm{g}$, (c) Rate capabilities and cycle performance of three dimensional graphene nanospheres and carbon black electrodes, (d) Long term cycling stability of three dimensional graphene nanospheres as anode electrode at $0.5 \mathrm{~A} / \mathrm{g}$ and $2.5 \mathrm{~A} / \mathrm{g}$

电曲线中，放电电压平台基本消失，这是因为 SEI 膜是锂离子的导体和电子的绝缘体，当三维石墨烯 纳米球电极被 SEI 膜覆盖后, 有机电解液的还原反 应就停止了，而锂离子却可以在电极中可逆的嵌入 和脱出。

图 4(c)对比了不同电流密度下三维石墨烯纳 米球和炭黑的倍率性能, 可以看到在不同电流密 度条件下，三维石墨烯纳米球作为锂离子电池负 极材料的比容量大于炭黑作为锂离子电池负极材 料, 并且随着电流密度的逐渐增大，三维石墨烯纳 米球电极与炭黑电极构成的电池的比容量差距逐 渐加大, 当电流密度为 $0.05 \mathrm{~A} / \mathrm{g}$ 时, 电池容量差为 $34.5 \mathrm{mAh} / \mathrm{g}$; 当电流密度为 $1 \mathrm{~A} / \mathrm{g}$ 时, 电池容量差 为 $42.3 \mathrm{mAh} / \mathrm{g}$, 这表明三维石墨烯纳米球作锂离 子电池负极的倍率性能优于炭黑作为锂离子电池 负极材料时的倍率性能。

图 4(d)为三维石墨烯纳米球作为锂离子电池 的负极材料时, 不同电流密度下的循环稳定性 能。在 $0.5 \mathrm{~A} / \mathrm{g}$ 的电流密度下, 初次放电容量为 $365.2 \mathrm{mAh} / \mathrm{g}$, 而第二次放电比容量为 $176 \mathrm{mAh} / \mathrm{g}$,
不可逆的放电比容量高达 $189.2 \mathrm{mAh} / \mathrm{g}$ 。同样在电流密 度为 $2.5 \mathrm{~A} / \mathrm{g}$ 下, 不可逆的放电比容量为 $125 \mathrm{mAh} / \mathrm{g}$ 。 这是因为三维石墨烯纳米球电极材料仅为纳米级 尺寸, 因而纳米球与纳米球之间相互交错的缝隙 是纳米数量级别。这种微观结构使锂离子的嵌入深 度很浅, 过程短, 这为锂离子提供了大量的嵌入空 间位置, 因此锂离子电池会具有比较高的初次放 电比容量, 同时还具有比较大的不可逆放电比容 量。最后三维石墨烯纳米球负极在充放电流密度为 $0.5 \mathrm{~A} / \mathrm{g}$ 和 $2.5 \mathrm{~A} / \mathrm{g}$ 下, 经过 100 次充放电后, 电池 的放电比容量分别高达 173 和 $111.1 \mathrm{mAh} / \mathrm{g}$, 电池 的容量损失几乎可以忽略不计。这表明三维石墨烯 纳米球作为锂离子电池的负极材料具有很好的循 环稳定性能。

\section{3 结论}

采用直流放电电弧法制备出三维石墨烯纳米球 材料, 并将它和商用的炭黑材料分别作为锂离子电 池的负极材料，测试其相关电化学性能。实验制备的 
三维石墨烯纳米球尺寸分布均匀，且尺寸分布范围 为 40 60 nm。在充放电电流密度为 $0.05 \mathrm{~A} / \mathrm{g}$ 下, 三 维石墨烯纳米球的初次放电容量高达 $485.9 \mathrm{mAh} / \mathrm{g}$, 而炭黑的初次放电容量仅为 $401 \mathrm{mAh} / \mathrm{g}$, 这表明三维 石墨烯纳米球作为锂离子电池负极材料比炭黑具有 更高的初次放电容量。三维石墨烯纳米球作为负极 在充放电流密度分别为 $0.5 \mathrm{~A} / \mathrm{g}$ 和 $2.5 \mathrm{~A} / \mathrm{g}$ 条件下，且 充放电次数为 100 次以后, 其电池的放电比容量几 乎没有衰减, 这表明三维石墨烯纳米球作为锂离子 电池的负极具有很好的循环稳定性。

\section{参考文献:}

[1] GEIM A K, NOVOSELOV K S. The rise of graphene. Nature Materials, 2007, 6(3): 183-191.

[2] RAO C N R, BISWAS K, SUBRAHMANYAM K S, et al. Graphene, the new nanocarbon. Journal of Materials Chemistry, 2009, 19(17): 2457-2469.

[3] ALLEN M J, TUNG V C, KANER R B. Honeycomb carbon: A review of graphene. Chemical Reviews, 2010, 110(1): 132-145.

[4] ZHANG L, CHEN Y S, YANG X, et al. Porous 3D graphene-based bulk materials with exceptional high surface area and excellent conductivity for supercapacitors. Scientific Reports, 2013, 3: 1408.

[5] LEE C G, WEI X D, HONE J, et al. Measurement of the elastic properties and intrinsic strength of monolayer graphene. Science, 2008, 321(5887): 385-388.

[6] BALANDIN A A, GHOSH S, LAU C N, et al. Superior thermal conductivity of single-layer graphene. Nano Letters, 2008, 8(3): 902-907.
[7] STANKOVICH S S, DIKIN D A, RUOFF R S, et al. Graphene-based composite materials. Nature, 2006, 442(7100): 282-286.

[8] LIN Y M, DIMITRAKOPOULOS C, JENKINS $\mathrm{K}$ A, et al. $100-\mathrm{GHz}$ transistors from wafer-scale epitaxial graphene. Science, 2010, 327(5966): 662.

[9] LIU M, YIN X B, ZHANG X, et al. A graphene-based broadband optical modulator. Nature, 2011, 474(7349): 64-67.

[10] KIM K S, ZHAO Y, HONG B H, et al. Large-scale pattern growth of graphene films for stretchable transparent electrodes. Nature, 2009, 457(7230): 706-710.

[11] ZHU Y W, MURALI S, RUOFF R S, et al. Carbon-based supercapacitors produced by activation of graphene. Science, 2011, 332(6037): 1537-1541.

[12] DENG M, YANG X, CHEN H Z, et al. Electrochemical deposition of polypyrrole / graphene oxide composite on microelectrodes towards tuning the electrochemical properties of neural probes. Sensors and Actuators B-Chemical, 2011, 158(1): 176-184.

[13] XU M S, FUJITA D S, HANAGATA N, et al. Perspectives and challenges of emerging single-molecule DNA sequencing technologies. Small, 2009, 5(23): 2638-2649.

[14] XU M S, CHEN H Z, YANG X, et al. Unique synthesis of graphenebased materials for clean energy and biological sensing applications. Chinese Science Bulletin, 2012, 57(23): 3000-3009.

[15] GUO P, SONG H H, CHEN X H. Electrochemical performance of graphene nanosheets as anode material for lithium-ion batteries. Electrochemistry Communications, 2009, 11(6): 1320-1324.

[16] PAN D Y, WANG S, ZHAO B, et al. Li storage properties of disordered graphene nanosheets. Chemistry of Materials, 2009, 21(14): 3136-3142. 